\title{
Contaminación del agua
}

Virgilio Ordóñez Ramirez

Ingeniería Industrial UPS-GUAYAQUIL

\section{$m$}

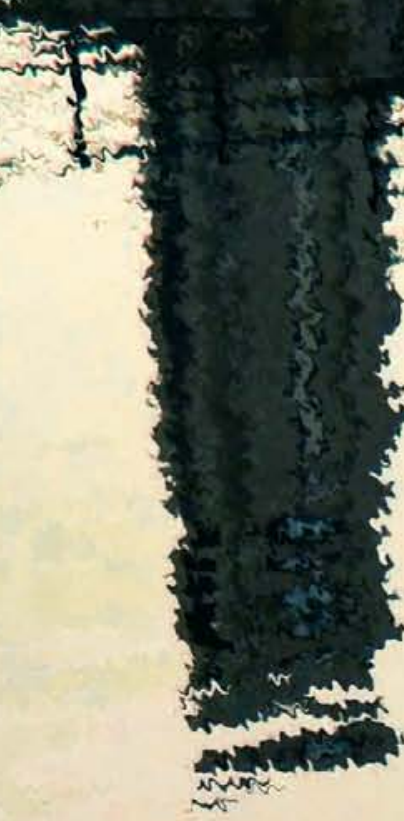

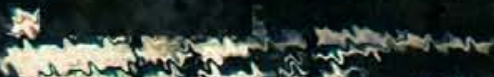

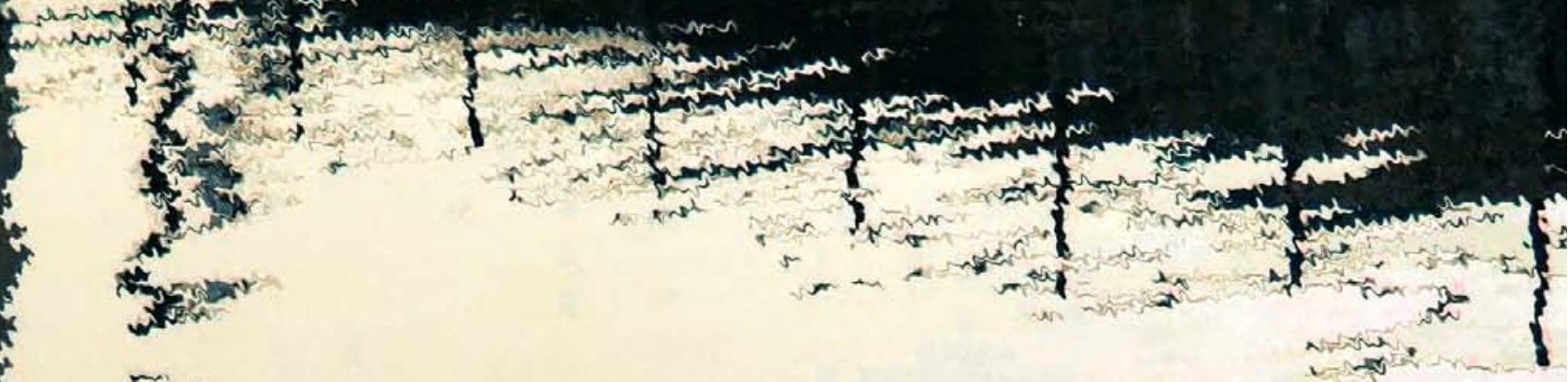

was

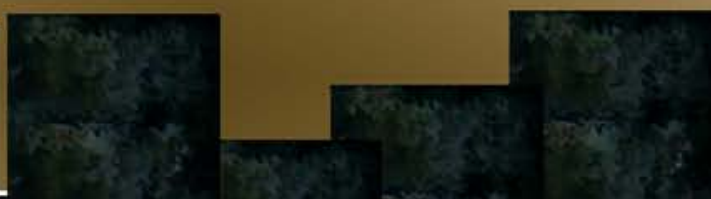


El Golfo de Guayaquil es el accidente geográfico más importante de la costa Sudamericana. Tiene una entrada de 200 Kilómetros de largo desde la Península de Santa Elena, en Ecuador, penetra al litoral ecuatoriano hasta $120 \mathrm{Km}$. Tiene dos ecosistemas: El Estero Salado, de $60 \mathrm{Km}$. de largo y una profundidad promedio de 9.45 metros; y el río Guayas con $90 \mathrm{Km}$ de largo. Ambos conductos se comunican entre sí por medio del canal Cascajal. Uno de los asentamientos humanos más importantes del Golfo es la ciudad de Guayaquil, limitada por los dos cuerpos de agua el Estero Salado (agua salada) por el Oeste y el Río Guayas (agua dulce) por el Este. Guayaquil es la ciudad que genera la mayor cantidad de desechos, un porcentaje de los cuales llega a dos sistemas de alcantarillado el pluvial y sanitario.

Alrededor de 540 industrias asentadas en Guayaquil evacuan el $25 \%$ del total de las cargas orgánicas, el $75 \%$ restante corres- ponden a las aguas servidas domésticas sin tratamiento de la ciudad y zonas periféricas, además solo el $3 \%$ de las industrias tratan sus desechos adecuadamente y por lo menos 524 industrias contaminan al río y al estero. Así mismo en Guayaquil se evacua diariamente 691 metros cúbicos de aguas servidas, el 10\% va directamente al Guayas, un $66 \%$ lo recibe por uno de sus afluentes, el Daule y al Estero salado llega el $24 \%$ de las aguas de alcantarillado.

Entre los problemas ambientales más relevantes tenemos:

El relleno hidráulico sin previo estudio de impacto ambiental ha causado la proliferación de enfermedades en tales áreas
- Inundaciones.- Los asentamientos a orillas del Estero Salado y Río Guayas son los sitios más susceptibles a inundaciones por desbordamientos, a esto se suma el pésimo sistema de alcantarillado pluvial el cual se tapona en épocas de lluvias.

- Los asentamientos cerca de las riberas del Estero Salado y del Río Guayas.- La búsqueda de lugares no ocupados ha dado origen a los asentamientos humanos en este sector estrechando su cauce natural, arrojando sus excretas y basuras directamente sobre estos cuerpos, lo cual ha alterado el equilibrio ecológico.

- Obras en áreas de asentamientos informales sin control.- El relleno hidráulico sin previo estudio de impacto ambiental ha causado la proliferación de enfermedades en tales áreas, debido a que se ha extraído arena del lecho contami-

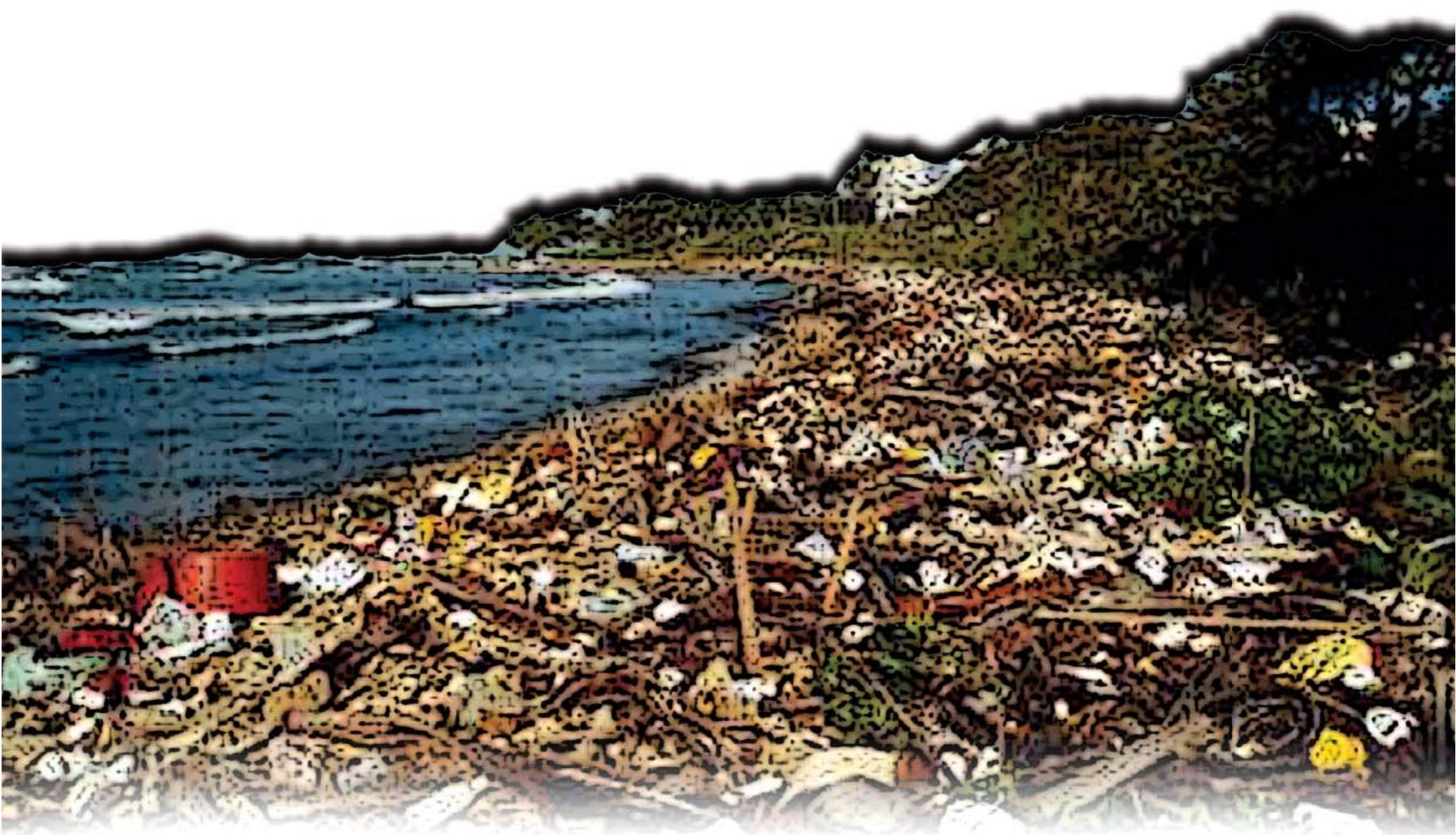


nado del río Guayas vertiéndose en el ambiente y llegando de esta manera hasta los seres humanos que habitan el área.

En estos ecosistemas se han determinado puntos críticos de contaminación como por ejemplo en el Estero Salado, zona cercana a los puentes Miraflores, Perimetral, Isla Trinitaria y en el río Guayas en el área del Puerto Marítimo, donde por la calidad del agua de acuerdo a las características físico-químicas se las cataloga como zonas fuertemente intervenida, con aguas anóxicas o altamente deficitarias de oxígeno, alta de-

\footnotetext{
Por otra parte, es necesario que el muy Ilustre municipalidad de Guayaquil tome las acciones necesarias para propender a la reubicación de las áreas con asentamientos marginales ubicados en las riberas del estero Salado...
}

manda bioquímica de oxígeno como resultado de la presencia de substancias reductoras, aguas fuertemente eutrofizadas por el aporte de substancias orgánicas e inorgánicas; evidente contaminación por hidrocarburos del petróleo debido tanto a los efluentes de origen industrial y doméstico como a la evacuación de las sentinas de las embarcaciones que navegan por sus aguas $y$, una evidente contaminación por microorganismos patógenos, ocasionando serios daños a la calidad del aire, agua, sedimentos, flora, fauna y sobre las actividades socio económicas de la población asentada en esos sectores.

Ante tales efectos negativos que la ciudad de Guayaquil está ocasionando a estos ecosistemas, es necesario medidas correctivas que propicien a mitigar estos efectos, para lo cual se sugiere:

- Que la Autoridad competente presione a las industrias a construir sistemas de tratamiento de aguas residuales a fin de que evacuen efluentes que cumplan con los rangos establecidos en el reglamento de ley de aguas y tengan la calidad necesaria para no continuar contaminando los cuerpos receptores.

- Solicitar al sector industrial la realización de estudios de impacto ambiental en caso de infraestructuras nuevas.

- Que la Dirección del Medio Ambiente del Municipio continúe con su programa de auditorias ambientales al sector industrial y aplicar las normativas vigentes para controlar estas actividades.

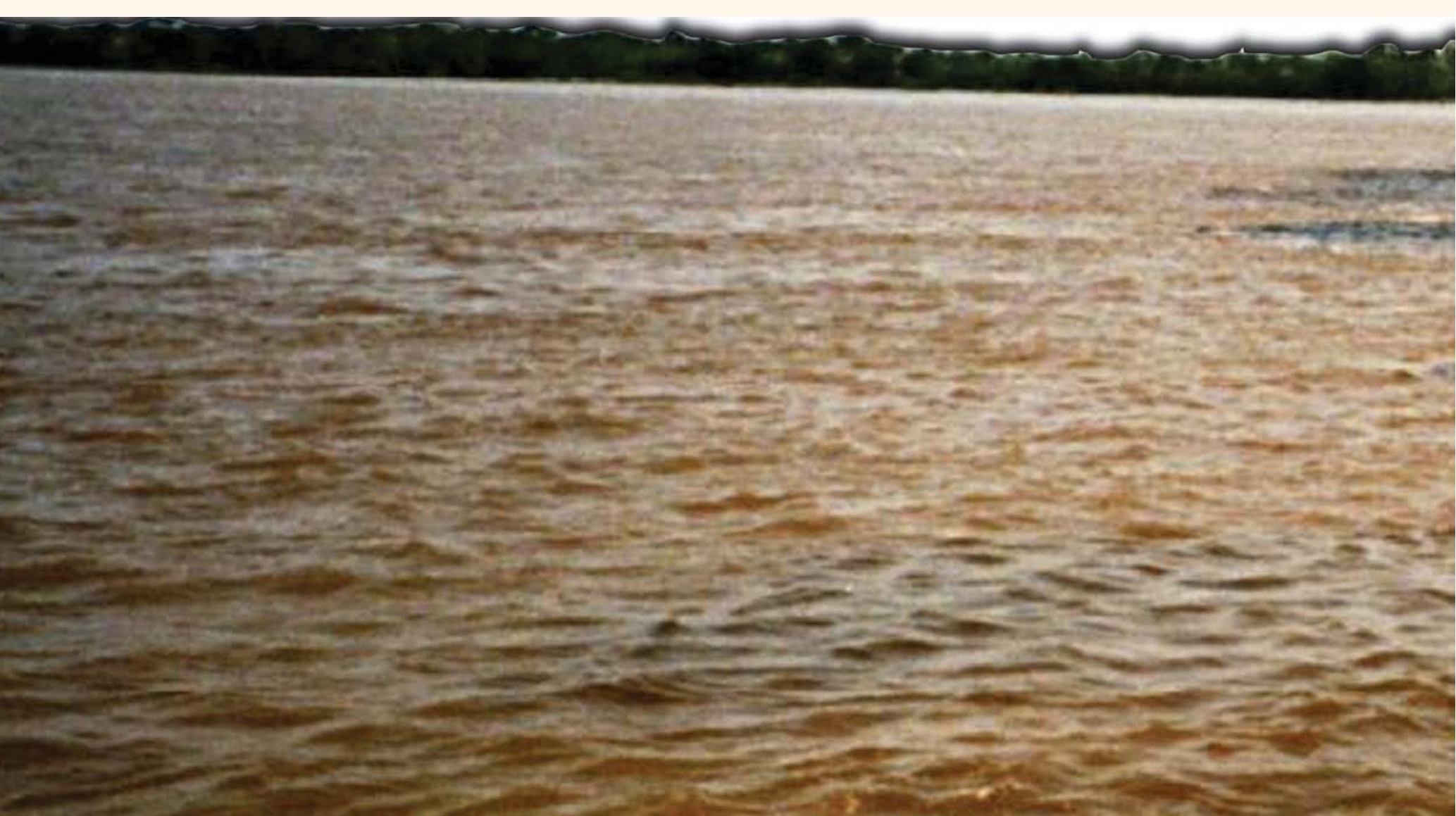


- Por otra parte, es necesario que el Muy llustre Municipalidad de Guayaquil tome las acciones necesarias para propender a la reubicación de las áreas con asentamientos marginales ubicados en las riberas del estero Salado para de esta manera dar lugar a extender la construcción del malecón del Salado y eliminar así las descargas de contaminantes que se producen y que son imposibles de controlar actualmente.

- Educación Ambiental a la ciudadanía, en tal sentido fortalecer campañas de concienciación a la población sobre la contaminación de estos ecosistemas, requiriéndose para tal efecto, de la colaboración de las autoridades municipales, planteles educativos para dotar a esa población de los elementos necesarios y lógicamente para aplicar las ordenanzas de control sanitario necesarias.
Crear una legislación para que las industrias nuevas que se creen en el país así como las ampliaciones o nuevas instalaciones que requieran hacer las actividades industriales, se las ubique en las ciudades más pobres, de poca producción para permitir el desarrollo en las mismas y evitar la migración interna de sus habitantes hacia las grandes ciudades
Crear una legislación para que las industrias nuevas que se creen en el país así como las ampliaciones o nuevas instalaciones que requieran hacer las actividades industriales, se las ubique en las ciudades más pobres, de poca producción para permitir el desarrollo en las mismas y evitar la migración interna de sus habitantes hacia las grandes ciudades, en las cuales al momento es imposible satisfacer las necesidades de sus habitantes y menos mejorar la calidad de vida. Con esto, estamos minimizando los factores de contaminación en las grandes ciudades y promoviendo el desarrollo económico de las ciudades más pequeñas, siempre y cuando se lo realice mediante un plan estratégico coordinado, que asegure que en las pequeñas comunidades no se deteriore el ambiente.

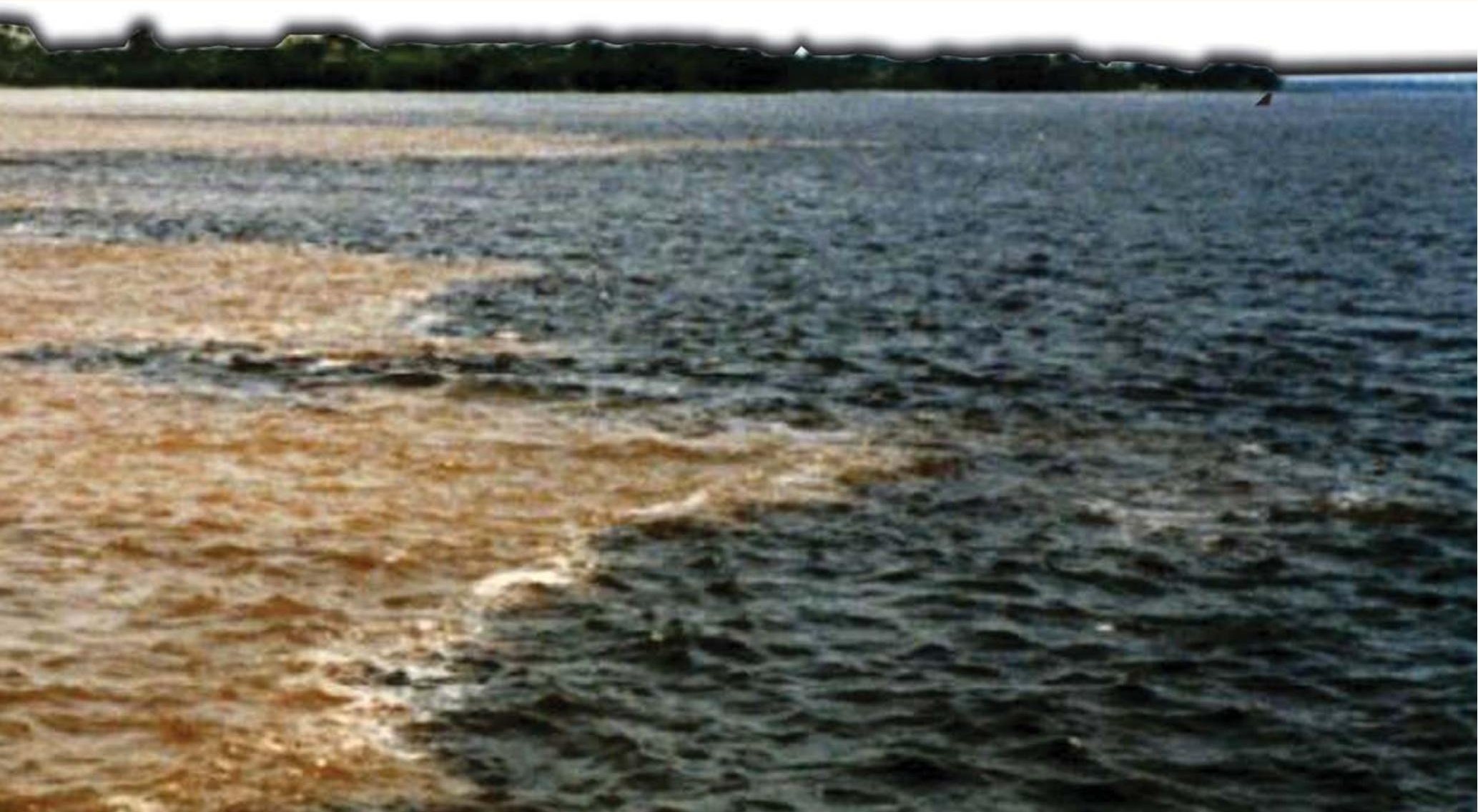

